\title{
RESENHA
}

\section{Entre ideias e letras grafadas: intelectuais, política e cultura escrita REVIEW}

Between ideas and inscribed letters: intellectuals, politics and written culture

\author{
Karla Simone Willemann Schütz ${ }^{1}$
}

VENÂNCIO, Giselle Martins (Org.). Intelectuais e palavra impressa. Niterói: Eduff, 2016.

Redes de sociabilidade, geração e cultura política: conceitos que já não são mais desconhecidos dos historiadores brasileiros, dentre esses, pesquisadores que se lançam a investigações que tomam por objetos publicações literárias, culturais, jornalísticas, historiográficas e aqueles responsáveis pela sua produção ou difusão. Dentro deste panorama de pesquisa se apresenta o livro Intelectuais e palavra impressa. Lançada em 2016, a obra tem como organizadora Giselle Martins Venâncio, professora do departamento de História e do Programa de Pós-Graduação em História da Universidade Federal Fluminense (UFF) e pesquisadora vinculada ao Núcleo de Pesquisa em História Cultural instalado nessa mesma instituição. Ao longo de sua trajetória como historiadora, Venâncio buscou investigar temas relativos à história da cultura escrita, tendo como uma das principais preocupações interrogar os usos sociais dos objetos impressos, bem como os conflitos e estratégias que podem nestas materialidades estarem inscritos.

Nota-se que a obra supracitada é fruto dos diversos trabalhos acadêmicos nos quais Venâncio esteve envolvida como orientadora. Os capítulos do livro são recortes de pesquisas, algumas concluídas e outras em andamento, que estão situadas nos mais diversos espaços acadêmicos da UFF, da graduação à pós-graduação e, portanto, têm como autores pesquisadores em diversos graus de formação (de graduandos a doutores) aglutinados em torno do tema da palavra impressa. Sendo assim, de uma maneira geral, o livro permite pensar em como a temática da Cultura Escrita em convergência com a História Cultural e Política é passível de ser abordada. Exibindo um breve panorama dos limites e das possibilidades que se abrem aos pesquisadores que investem nessas áreas de pesquisa e onde todos esses conceitos acima mencionados são de alguma

\footnotetext{
${ }^{1}$ Doutoranda do Programa de Pós-Graduação em História da Universidade do Estado de Santa Catarina. Bolsista PROMOP-UDESC. E-mail: karlawschutz@gmail.com

Recebido em 22 de maio de 2017. Aprovado em 10 de agosto de 2017.
} 
maneira instrumentalizados, o livro proporciona reflexões que tangenciam, por exemplo, a forma de organização e ação de intelectuais ou dos grupos a eles vinculados.

Os trabalhos abordam períodos diversos, que vão desde o final do século XIX até meados da década de 1970. Os espaços, por seu turno, abrangem distintas regiões do território brasileiro e chegam até mesmo a Portugal. Dada essa pluralidade, não é surpresa que os objetos abordados acompanhem essa variedade de temporalidades e ambientes. São eles revistas, publicações institucionais, livros, jornais e produções científicas que são observados desde seu processo de editoração até a formação de colunas específicas dentro de periódicos, onde ideias e ideais são disseminados.

De forma a situar e sistematizar essas pesquisas na obra, a organizadora operou no livro uma divisão em dois eixos distintos: no primeiro aborda análises de alguns projetos editoriais, publicações e coleções, já no segundo se colocam como matérias das investigações produções escritas que corroboram a ação política e social de seus próprios produtores, bem como da estrutura de poder ao qual estariam relacionados. Os trabalhos, assim, estão inseridos num movimento historiográfico que busca refletir sobre os vários veículos transmissores de ideias e tramas políticas.

Em relação à primeira parte do livro, dividida em 5 capítulos, observa-se que as pesquisas elegem como objetos tanto os frutos de projetos editoriais - catálogos, periódicos, coleções literárias e livros históricos comemorativos cultura escrita - quanto a atuação de determinados intelectuais nesses projetos e quais os objetivos e ideias presentes no meio cultural e social que os circundava. Desta maneira, nos dois primeiros capítulos aparecem projetos editoriais de instituições ligadas ao Estado brasileiro. As pesquisadoras Michele Agostinho e Mariana Simões interrogam, respectivamente, parte da trajetória da revista científica Arquivos do Museu Nacional (periódico editado pelo Museu Nacional) e a série Publicações do Arquivo Público do Império.

Enquanto isso, nos três últimos capítulos deste primeiro eixo, os olhares direcionados à cultura escrita são um pouco distintos. Tomando como objeto a Revista Brasiliense, periódico produzido pela Editora Brasiliense, Renan Rubin Caldas tenta compreender as redes de sociabilidades estabelecidas ao redor da revista e do intelectual Elias Chaves Neto. Para tanto, aquilo que é veiculado pela revista é pensado conjuntamente ao panorama político brasileiro entre os anos de 1955 e 1960, pois sendo o objetivo estabelecer de que maneira se deram as conexões intelectuais dentro da revista, se torna imprescindível perceber as diversas orientações políticas que a 
publicação congregava e de que modo conviviam nesse espaço diversos colaboradores com, inclusive, orientações políticas diferentes.

O historiador Sérgio Buarque de Holanda também figura entre os intelectuais abordados no livro. André Furtado, ao observar o desenvolvimento da produção da coletânea de História Geral da Civilização Brasileira, lançada por Sérgio Buarque em 1972, buscou esmiuçar as contingências que envolviam esse processo, bem como outros aspectos que aparecem no e em torno desse empreendimento editorial, como parte da divulgação, repercussão, polêmicas e certos embates.

O último dos capítulos concernentes a esta primeira parte da obra é de autoria de Mariana Rodrigues, que tem como foco de sua investigação as duas edições de $O$ Paraná no Centenário, livro “comemorativo" produzido por José Francisco da Rocha Pombo. A primeira destas edições foi lançada em 1900, enquanto a segunda é relançada em 1980, por iniciativa da Secretaria de Esporte e Cultura do Paraná e da editora José Olympio. Tomando ambos os acontecimentos como sintomáticos, Rodrigues apresenta uma comparação entre as duas edições, rastreando nesse processo indícios que elucidam seu longo período de "silenciamento" e as hipóteses que poderiam explicar a motivação para o seu relançamento 80 anos depois.

Enquanto o primeiro eixo de Intelectuais e palavra impressa faz uma espécie de história da imprensa, pois toma como objetos as próprias produções e os seus "produtores", o segundo eixo mostra investigações que tomam a palavra impressa como evidência das ideias e teorias que circulavam em determinados espaços e temporalidades no Brasil e em Portugal.

Inicia a segunda parte da obra o capítulo produzido Felipe Cazetta, que "atravessando" o oceano atlântico e chegando a Portugal, utiliza dois periódicos portugueses - Nação Portuguesa e Ordem Nova - para analisar as concepções dos intelectuais ligados ao Integralismo Lusitano acerca da ditadura e da República de 1910 em Portugal. Cazetta acredita que este movimento integralista tenha exercido influencia no regime salazarista que vigorou entre a década de 1930 e 1970 no país - apesar da baixa representatividade que este grupo teve em relação às questões decisórias. O autor então busca nestes periódicos compreender que ideais eram estes.

O segundo capítulo de Felipe Oliveira da Silva, por seu turno, tenta compreender o ambiente político-cultural no qual são disseminadas ideias acerca da natureza e a sua preservação por meio das edições da Revista Florestal lançadas entre 1929 e 1932. Operando esse movimento Silva chega a conclusões interessantes, 
reparando que essa "onda verde" difundida entre alguns intelectuais das décadas de 1920 e 1930 se apresenta no periódico a partir de discursos contraditórios, pois apesar de uma defesa a preservação de "nossas florestas", a revista tinha como principal público alvo e principais patrocinadores grandes indústrias da produção de madeira.

No terceiro capítulo deste eixo aparecem as teorias raciais propaladas no final do século XIX e início do século XX. Raquel Braun Figueiró, ao observar produções escritas diversas - um estudo de antropologia e textos historiográficos publicados no periódico Correio do Povo de autoria do médico porto-alegrense Sebastião Leão entre anos de 1895 e 1903 - tenta esmiuçar de que maneira esse intelectual absorve e se apropria das ideias raciais que circulavam mundialmente naquele momento. Sendo assim, Figueiró demonstra como essas são trazidas à realidade brasileira e como Leão utiliza sua posição privilegiada na sociedade gaúcha e sua rede de sociabilidades como possibilidade tangível de disseminar suas opiniões e seus pontos de vista.

Já o último capítulo do eixo e do livro traz uma discussão acerca das demandas políticas referentes a alguns setores das Forças Armadas brasileiras, em especial as que vinham do grupo dos sargentos. A fonte na qual Bruno Guedes de Carvalho busca essas solicitações é uma coluna publicada diariamente no jornal Última Hora, denominada Plantão Militar. Como se nota já no nome, tal coluna era uma produção voltada especificamente para o público militar e era inclusive de autoria de um sargento reformado do exercito: João Batista de Paula. Depois de analisar de que maneira apareciam essas demandas entre fevereiro de 1957 e $1^{\circ}$ de abril de 1964, Carvalho acaba por perceber que as solicitações que vinham desta camada do exército mostram indícios importantes que vão ao encontro do senso comum, que acredita haver nos ideais e pensamentos ligados às Forças Armadas uma homogeneidade plena.

Como é possível perceber ao longo dos capítulos, o ambiente político-social e a personalidade dos intelectuais são mesclados com a tentativa de operar um movimento de análise onde estes objetos se explicam mutuamente. Nesse sentido, vigora a concepção de que as produções referentes a essa cultura escrita não são uma "via de mão-única”, e que homens e mulheres pelas quais elas são elaboradas não estão "sujeitados" ao ambiente e tempo do qual provém, da mesma forma que esses agentes não operam sozinhos como "gênios" que interferem na realidade social e cultural a qual pertencem. Nessa toada, pode ser trazida à cena a própria ideia de "intelectual mediador", noção que timidamente aparece no já clássico texto de Jean-François 
Sirinelli ${ }^{2}$, mas que é interessantemente operacionalizada por Angela de Castro Gomes e Patrícia Hansen no livro por elas organizado, Intelectuais Mediadores (2016), onde há inclusive um capítulo de autoria de Giselle Martins Venâncio, principal responsável pela obra aqui resenhada.

Em Intelectuais Mediadores as autoras buscam por meio da noção de mediação dar diferentes gradações ao já bastante fluído conceito de Intelectual. Esse movimento intenciona, por fim, trazer mais riqueza e contemplar um maior número de autores, homens e mulheres, que operam com suas ideias e ações políticas nos mais diversos espaços da sociedade. Pensando nas pesquisas apresentadas ao longo do livro de Venâncio e naquelas que aparecem na obra de Angela de Castro Gomes e Patrícia Hansen, nota-se que existem inúmeros pontos de encontro e que alguns dos personagens que são abordados em Intelectuais e palavra impressa poderiam ser também pensados como intelectuais mediadores, pois atuam como intermediários entre certo tipo de conhecimento/informação e seu público.

Sendo assim, para romper com a dicotomia que constrói uma via direta entre a produção dos elementos aqui abordados como provenientes da cultura escrita e a recepção destas produções, entram em cena estes intelectuais, como por exemplo, o jornalista militar que "adapta" as demandas a serem publicadas no jornal ou o médico que se apropria das teorias raciais que circulavam no mundo no momento em que ele escrevia e também as publica em um periódico. Esses agentes transformam e reelaboram ideias já existentes e possivelmente já produzidas por outro tipo de intelectual. Dessa maneira fazem também emergir uma reflexão acerca dos fenômenos, atividades e práticas de circulação e apropriação que englobam essas produções escritas.

Por fim, esses homens não são apenas "vulgarizadores" de determinado pensamento, e assim como a figura do intelectual foi ativada pela História Política desenvolvida, sobretudo, a partir da década de 1980. A noção de intelectual mediador participa de um processo que busca trazer novos tons às análises históricas acerca das produções culturais de diversas sociedades e tempos e ao modo como essas produções sejam elas da cultura escrita ou não - são apropriadas e estão relacionadas também ao estabelecimento de redes de sociabilidade, bem como podem se referir à gerações e culturas políticas específicas como demonstram as pesquisas aqui brevemente sintetizadas.

\footnotetext{
${ }^{2}$ SIRINELLI, Jean-François. Os intelectuais In: RÉMOND, René. Por uma história política. Rio de Janeiro: FGV, 1996. pp.231-269.
} 


\section{Referências:}

GOMES, Angela de Castro; HANSEN, Patricia Santos (Orgs.). Intelectuais Mediadores: práticas culturais e ação política. Rio de Janeiro: Civilização Brasileira, 2016.

SIRINELLI, Jean-François. Os intelectuais In: RÉMOND, René. Por uma história política. Rio de Janeiro: FGV, 1996. pp.231-269. 